\title{
METRIC MEASUREMENTS AND ATTACHMENT LEVELS OF THE MEDIAL PATELLOFEMORAL LIGAMENT: AN ANATOMICAL STUDY IN CADAVERS
}

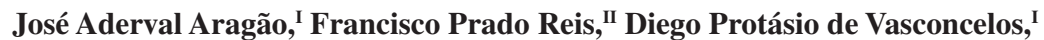 \\ Vera Lúcia Corrêa Feitosa, ${ }^{\mathrm{I}}$ Marco Antonio Prado Nunes ${ }^{\mathrm{II}}$
}

doi: $10.1590 / \mathrm{S1807-59322008000400021}$

Aragão JA, Reis FP, Vasconcelos DP, Feitosa VLC, Nunes MAP. Metric measurements and attachment levels of the medial patellofemoral ligament: an anatomical study in cadavers. Clinics. 2008;63:541-4.

OBJECTIVE: To determine the metric measurements and to verify the attachment levels of the medial patellofemoral ligament in human cadavers.

METHODS: Seventeen knees (eight right and nine left knees) from 10 cadavers (nine male and one female) were dissected and stored in a $10 \%$ formaldehyde solution. All of the knees were whole and did not show any macroscopic signs of injuries.

RESULTS: The medial patellofemoral ligament was present in $88 \%$ of the knees studied, localized transversally between the medial femoral epicondyle and the medial margin of the patella. Its dimensions were quite variable, even between the knees of the same individual. The width of the patellar insertion ranged from 16 to $38.8 \mathrm{~mm}$, with a mean of $27.90 \mathrm{~mm}$, and its mean length was $55.67 \mathrm{~mm}$. The margins of the ligament were concave or rectilinear. At the upper margin, the concave form predominated and was better characterized, while at the lower margin, the rectilinear form predominated.

CONCLUSIONS: The medial patellofemoral ligament is a very distinct structure with variable anatomical aspects and is always located in a plane inferior to the vastus medialis obliquus muscle.

KEYWORDS: Anatomy. Knee. Ligaments. Patella. Luxation of the patella.

\section{INTRODUCTION}

The medial patellofemoral ligament (MPFL) was first described in 1979 by Warren and Marshall; ${ }^{1}$ none of the editions of the Nomina Anatomica mention this ligament. These authors described three anatomical planes at the level of the anteromedial surface of the knee, which they named layer 1, the most superficial; layer 2, the intermediate; and layer 3 , the deepest, represented by the joint capsule of the knee. The MPFL was found in layer 2, between the medial femoral epicondyle (MFE) and the patella.

According to several authors, ${ }^{1-8}$ the ligament is present in

I Departamento de Morfologia da Universidade Federal de Sergipe, Aracaju/ SE, Brazil.

II Laboratório de Anatomia da Universidade Tiradentes, Aracaju/SE, Brazil.

Email: jaafelipe@infonet.com.br

Received for publication on March 18, 2008

Accepted for publication May 23, 2008 all knees. On the other hand, Conlan et al. ${ }^{9}$ found the MPFL in $88 \%$, while Reider et al. ${ }^{10}$ only found it in $35 \%$ of the cases and considered it to be a thickening of the joint capsule of the knee. There is variation in the MPFL between individuals, but not between the knees of the same individual. ${ }^{2,5} \mathrm{An}$ anatomical space of triangular shape formed by the MPFL with the tendon of the adductor magnus muscle (TAMM) and the vastus medialis obliquus (VMO) was described by Warren and Marshall. ${ }^{1}$ From a biomechanical point of view, the MPFL is considered to be the main medial static stabilizing structure of the patella. ${ }^{11}$ Biomechanical studies have also revealed that this ligament is responsible for around $60 \%$ of the medial constraining strength of the patella., ${ }^{5,912-14}$ It is considered to be the first and most important structure that is injured in cases of acute luxation of the patella, ${ }^{9,12,15}$ and it is also important in proprioception of the knee musculature. ${ }^{2,16}$

Anatomical and biomechanical studies on the MPFL have enabled its repair or reconstruction utilizing different surgical techniques, which has led to improved results in 
the surgical treatment of acute luxation of the patella. ${ }^{17,18-20}$ However, there are disagreements in the medical community regarding the anatomy of this ligament. ${ }^{14}$ The purpose of the present study was to contribute to the knowledge of the anatomy, relationships, and anatomical variations of the MPFL in adult human cadavers.

\section{MATERIAL AND METHODS}

Seventeen knees (eight right and nine left knees) from 10 cadavers (nine male and one female) were dissected and stored in a $10 \%$ formaldehyde solution. All of the knees were whole and did not appear to show any signs of injuries. The cadavers belonged to the anatomy laboratories of the Federal University of Sergipe and Tiradentes University, in Aracaju, State of Sergipe. They had been obtained in accordance with Law No. 8.501, enacted November 30, 1992, which deals with the use of unclaimed corpses for the purposes of studies and research. The present study was approved by the Ethics Committee of the Universidade Federal de Sergipe, under protocol number 0075.0.107.000-06. To dissect the anatomical planes, an initial incision was made on the anterior face of the knee, extending upwards to $2 \mathrm{~cm}$ above the upper margin of the patella and downwards to the tuberosity of the tibia. From these points, two parallel transverse incisions were made in the lateromedial direction on the knee. After pulling back the skin and subcutaneous cellular tissue, the distal insertion of the vastus medialis muscle was exposed. This was removed from its insertion at the medial margin of the patella, where there was a space between the vastus medialis muscle and the joint capsule of the knee. This muscle, together with the TAMM, served as a reference for identifying and dissecting the MPFL from the medial margin of the patella to the medial femoral epicondyle (MFE). The patella was divided into three thirds: upper, middle, and lower. The length and width of the insertions and the width of the middle portion of the ligament were measured by means of a digital pachymeter. All of the data were analyzed and interpreted using descriptive statistics.

\section{RESULTS}

The MPFL was present in 15 (88\%) of the 17 knees studied, and was arranged transversally between the MFE and the medial margin of the patella (Fig. 1). In two knees (12\%), the MPFL was not found. In these cases, greater adherence between layers 1 and 2 as designated by Warren and Marshall ${ }^{1}$ was observed. The general anatomical aspects and the dimensions of the MPFL were quite variable, even between the knees of the same individual. In two cadavers, the ligament was found in only one of the knees.

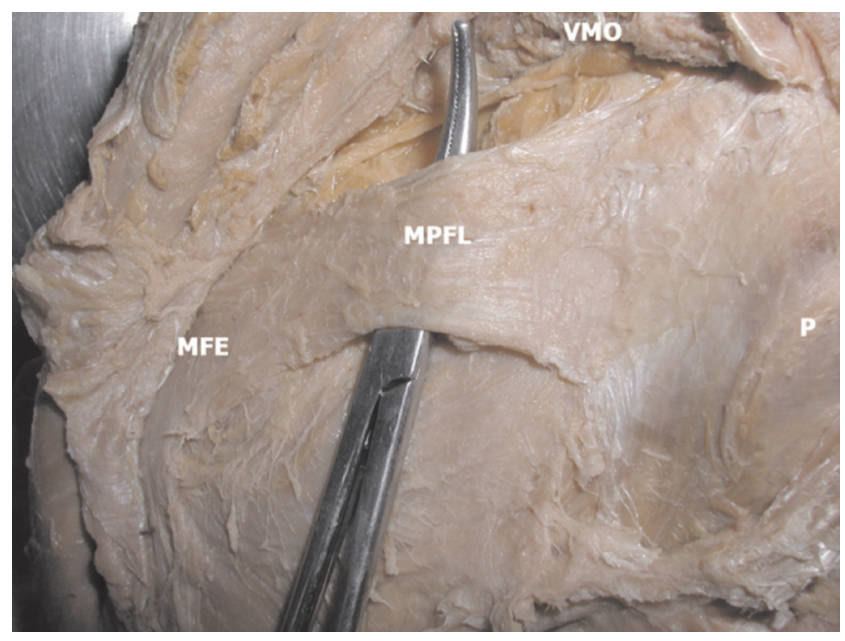

Figure 1 - The medial patellofemoral ligament. MPFL - medial patellofemoral ligament; VMO - vastus medialis obliquus; MFE - medial femoral epicondyle; $\mathrm{P}$ - patella

All of the ligaments were located in a plane inferior to the VMO. The fibers of $12(80 \%)$ of the ligaments were found to be partially adhered to the deep face of the VMO. In one knee, the MPFL was found to be adhered to the deep face of the vastus intermedialis muscle. After resection of layer 1 as designated by Warren and Marshall, ${ }^{1}$ we found that the ligament, the VMO, and the TAMM anatomically delimited a triangular area (Fig. 2).

The patellar insertion of the MPFL occurred at different levels along the medial margin of the patella: two (13\%), upper third; one (7\%), middle third; six (40\%), upper third and middle third; two (13\%), middle and lower thirds; and four $(27 \%)$, along the whole medial length of the patella. The width of the patellar insertion varied between 16 and 38.8 $\mathrm{mm}$, with a mean of $27.90 \mathrm{~mm}$.

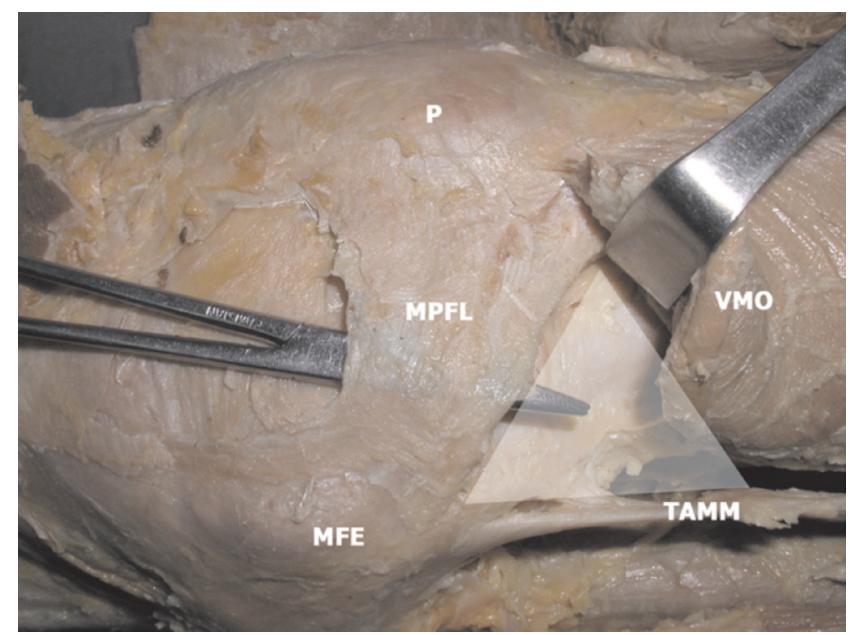

Figure 2 - Triangular area between the MPFL, VMO and TAMM. MPFL - medial patellofemoral ligament; VMO - vastus medialis obliquus; MFE - medial femoral epicondyle; P - patella; TAMM - tendon of the adductor magnus muscle 
In 13 ligaments (86\%), the femoral insertion of the MPFL occurred in the adductor tubercle (AT). This insertion was more distal than and anterior to the insertion of the TAMM, and more proximal than and anterior to the emergence of the medial collateral ligament. In ten cases $(67 \%)$, the ligaments appeared to be adhered to the distal superficial fibers of the TAMM, and in one case the ligament was related to the proximal fibers of the medial collateral ligament.

The margins of the MPFL were concave or rectilinear in shape. At the upper margin, the concave shape predominated and was better characterized, while at the lower margin, the rectilinear shape was predominated. There were three cases in which it was difficult to characterize the lower margin. The width of the middle portion of the MPFL was measured in the 12 cases in which it was possible to distinguish the lower margin of the ligament. Table 1 shows the measurements of the widths of the femoral and patellar insertions and the length of the MPFL.

Table 1 - Dimensions of the MPFL (mm)

\begin{tabular}{lccc}
\hline & Minimum & Maximum & Mean $( \pm$ SD $)$ \\
\hline Width of PI & 16.0 & 38.8 & $27.9( \pm 6,4)$ \\
Width of FI & 10.0 & 28.8 & $17.1( \pm 6,0)$ \\
Width of MP & 14.0 & 27.5 & $20.2( \pm 4,7)$ \\
Length & 46.0 & 58.0 & $55.6( \pm 2,9)$ \\
\hline
\end{tabular}

PI: patellar insertion; FI: femoral insertion; MP: middle portion

\section{DISCUSSION}

While several authors have suggested that the MPFL is present in all knees, ${ }^{1-8}$ Reider et al..$^{10}$ found the MPFL to be present in only $35 \%$ of their cases. In our study, the MPFL was present in $88 \%$ of the knees dissected. Amis et al. ${ }^{21}$ reported that other authors had not found the MPFL in the knees studied. In the present study, the MPFL was absent in only one knee each of of two cadavers. This finding is similar to that described by Conlan et al. ${ }^{9}$ The MPFL was always located in a plane inferior to the VMO, which is similar to the observations of several authors. ${ }^{1,2,5-7,9,20}$

With regard to anatomical relationships, the MPFL was found to be adhered to the deep face of the VMO in $80 \%$ of the cases and to the distal surface of the TAMM in $67 \%$. These findings appear to be similar to other authors' findings. ${ }^{2,5,6,14,21}$ We observed the anatomical relationship between the MPFL and the vastus intermedialis muscle that was described by Conlan et al. ${ }^{9,22,23}$ in only one of the knees we studied. Several authors ${ }^{5,8,12,21}$ have also described an anatomical relationship between the MPFL and the medial collateral ligament. We found this relationship in only one of our cases. We found that a relationship between the MPFL with the TAMM and the VMO as described by Warren and Marshall $^{1}$ and Tuxoe et al..$^{5}$ was present in all of the knees studied.

The typically-described location of the patellar insertion of the MPFL is the superomedial margin of the patella. ${ }^{1,25-10}$ This insertion is believed to occupy approximately half, or all of, the medial margin of the patella. ${ }^{16}$ According to Steensen et al., ${ }^{8,18}$ the mean width of this patellar insertion was $17 \mathrm{~mm}$. In our study, most of the ligaments were inserted in the upper third and/or middle third of the patella, and the mean width of the insertion was $27.90 \mathrm{~mm}$. In four knees, the insertion of the MPFL occurred along the whole medial margin of the patella.

According to Amis et al., ${ }^{21}$ there is a great deal of disagreement regarding the femoral insertion of the MPFL. Some authors have reported the insertion of the ligament to be in the AT. ${ }^{5,9}$ According to Feller et al, ${ }^{2}$ this insertion occurs in the anterior region of the MFE and not in the AT. For other authors, ${ }^{4,6,22}$ this insertion was found to be posterior to the MFE and distal to the AT, while Desio et al. ${ }^{12}$ reported that the insertion of the MPFL was in the medial collateral ligament. In our study, only two ligaments were not inserted in the AT. In one of them, the insertion was approximately 6 $\mathrm{mm}$ anterior to the AT, and in the other it was approximately $3 \mathrm{~mm}$ posterior to the AT. Smirk et al. ${ }^{6}$ emphasized that the region of the insertion of the MPFL is important because it may offer information on the best location for graft attachment during ligament reconstruction surgery. The femoral insertion had a more delicate macroscopic appearance and was around $10 \mathrm{~mm}$ less in width than the patellar insertion. For Steensen et al. ${ }^{18}$, this value was found to be $17 \mathrm{~mm}$. According to some authors, ${ }^{17,21,24}$ the femoral insertion is the main location for injuries to the MPFL in cases of acute luxation of the patella.

It was not possible to determine the lower margin of the MPFL in $20 \%$ of the cases. This finding was similar to that described by Tuxoe et al. ${ }^{5}$ We believe that this difficulty may be due to adherence between layers 1 and 2 as designated by Warren and Marshal. ${ }^{1}$ In the cases in which the lower margin of the MPFL was well defined, the mean width of the middle portion of the MPFL was $20.22 \mathrm{~mm}$. The width of the ligament measured at a distance of $10 \mathrm{~mm}$ from the AT was $19 \mathrm{~mm}$ according to Tuxoe et al. ${ }^{5}$; for Conlan et al., ${ }^{9}$ it was $13 \mathrm{~mm}$, and Reider et al., ${ }^{10}$ found a width ranging from 5 to $12 \mathrm{~mm}$. The mean length of the MPFL in our study was $55.67 \mathrm{~mm}$, which was similar to reports in the literature. ${ }^{5,6,20-22}$

Studies regarding the anatomical features of the MPFL $^{7,8,10,13,16,20}$ continue to provide the main source of information for understanding of the normal and pathological 
role of the biomechanical and/or clinical aspects of the patella.

\section{CONCLUSION}

The MPFL is a very distinct structure, with insertions at variable levels of the medial margin of the patella and the MFE. The MPFL was always located in a plane that was inferior to the VMO, and its lower margin was sometimes difficult to distinguish.

\section{ACKNOWLEDGMENTS}

The authors thank Ailton Vieira Santos for his expert help during dissection of the cadavers.

\section{REFERENCES}

1. Warren LF, Marshall JL. The supporting structures and layers on the medial side of the knee: an anatomical analysis. The Journal of bone and joint surgery. 1979;61:56-62.

2. Feller JA, Feagin JA, Jr., Garrett WE, Jr. The medial patellofemoral ligament revisited: an anatomical study. Knee Surg Sports Traumatol Arthrosc. 1993;1:184-6.

3. Hautamaa PV, Fithian DC, Kaufman KR, Daniel DM, Pohlmeyer AM Medial soft tissue restraints in lateral patellar instability and repair. Clinical orthopaedics and related research. 1998;349:174-82.

4. Nomura E, Horiuchi Y, Kihara M. Medial patellofemoral ligament restraint in lateral patellar translation and reconstruction. Knee. $2000 ; 1 ; 7: 121-7$

5. Tuxoe JI, Teir M, Winge S, Nielsen PL. The medial patellofemoral ligament: a dissection study. Knee Surg Sports Traumatol Arthrosc. 2002;10:138-40.

6. Smirk $\mathrm{C}$, Morris $\mathrm{H}$. The anatomy and reconstruction of the medial patellofemoral ligament. Knee. 2003;10:221-7.

7. Camanho GL. Estudo anatômico e artroscópico do ligamento femoropatelar medial. Acta Ortop Bras. 2003;11:145-9.

8. Steensen RN, Dopirak RM, Maurus PB. A simple technique for reconstruction of the medial patellofemoral ligament using a quadriceps tendon graft. Arthroscopy. 2005;21:365-70.

9. Conlan T, Garth WP, Jr., Lemons JE. Evaluation of the medial soft-tissue restraints of the extensor mechanism of the knee. The Journal of bone and joint surgery. 1993;75:682-93.

10. Reider B, Marshall JL, Koslin B, Ring B, Girgis FG. The anterior aspect of the knee joint. The Journal of bone and joint surgery. 1981;63:3516.

11. LeGrand AB, Greis PE, Dobbs RE, Burks RT. MPFL reconstruction. Sports Med Arthrosc. 2007;15:72-7.

12. Desio SM, Burks RT, Bachus KN. Soft tissue restraints to lateral patellar translation in the human knee. The American journal of sports medicine. 1998;26(1):59-65.

13. Sandmeier RH, Burks RT, Bachus KN, Billings A. The effect of reconstruction of the medial patellofemoral ligament on patellar tracking. The American journal of sports medicine. 2000;28:345-9.
14. Panagiotopoulos E, Strzelczyk P, Herrmann M, Scuderi G. Cadaveric study on static medial patellar stabilizers: the dynamizing role of the vastus medialis obliquus on medial patellofemoral ligament. Knee Surg Sports Traumatol Arthrosc. 2006;14:7-12.

15. Deie M, Ochi M, Sumen Y, Adachi N, Kobayashi K, Yasumoto M. A long-term follow-up study after medial patellofemoral ligament reconstruction using the transferred semitendinosus tendon for patellar dislocation. Knee Surg Sports Traumatol Arthrosc. 2005;13:522-8.

16. Boden BP, Pearsall AW, Garrett WE, Jr., Feagin JA, Jr. Patellofemoral Instability: Evaluation and Management. J Am Acad Orthop Surg. 1997;5:47-57.

17. Camanho GL. Tratamento da luxação femoro-patelar aguda pelo reparo do ligamento femoro-patelar medial. Acta Ortop Bras. 2005;13:10911 .

18. Steensen RN, Dopirak RM, McDonald WG 3rd. The anatomy and isometry of the medial patellofemoral ligament: implications for reconstruction. Am J Sports Med. 2004 Sep;32:1509-13. Epub 2004 Jul 20.

19. Schottle PB, Romero J, Schmeling A, Weiler A. Technical note: anatomical reconstruction of the medial patellofemoral ligament using a free gracilis autograft. 2008 May;128:479-84. Epub 2007 Feb 24.

20. Triantafillopoulos IK, Panagopoulos A, van Niekerk L. Isometric behavior of the reconstructed medial patellofemoral ligament using two different femoral pulleys: a cadaveric study. Med Sci Monit. 2007 Sep;13:BR181-187.

21. Amis AA, Firer P, Mountney J, Senavongse W, Thomas NP. Anatomy and biomechanics of the medial patellofemoral ligament. Knee. $2003 ; 10: 215-20$.

22. Nomura E, Inoue M, Osada N. Anatomical analysis of the medial patellofemoral ligament of the knee, especially the femoral attachment. Knee Surg Sports Traumatol Arthrosc. 2005 Oct;13:510-5. Epub 2005 May 13.

23. Panagiotopoulos E, Strzelczyk P, Herrmann M, Scuderi G. Cadaveric study on static medial patellar stabilizers: the dynamizing role of the vastus medialis obliquus on medial patellofemoral ligament. Knee Surg Sports Traumatol Arthrosc. 2006 Jan;14:7-12. Epub 2005 Jul 7.

24. Ahmad CS, Stein BE, Matuz D, Henry JH. Immediate surgical repair of the medial patellar stabilizers for acute patellar dislocation. A review of eight cases. The American journal of sports medicine. 2000;28:80410. 